\title{
Providing palliative care in humanitarian crises: Always something to offer
}

NB: The published version of the paper has further copyediting changes.

Richard A. Powell MSc, Director, MWAPO Health Development Group, Nairobi, Kenya Lisa Schwartz PhD, Arnold L. Johnson Chair in Health Care Ethics, Faculty of Health Sciences, McMaster University, Hamilton, Ontario, Canada

Elysée Nouvet PhD, Post-Doctoral Fellow in Humanitarian Healthcare Ethics, Department of Clinical Epidemiology \& Biostatistics, McMaster University, Hamilton, Ontario, Canada

Brett Sutton MBBS, Public Health Registrar, Burnet Institute, Melbourne, Australia Mila Petrova PhD, Research Associate, Primary Care Unit, Department of Public Health and Primary Care, University of Cambridge, Cambridge, UK

Joan Marston B Soc Sc, International consultant for children's palliative care, Assagay, South Africa

Daniel Munday PhD, Consultant in Palliative Medicine and Health Services Research, International Nepal Fellowship, Kathmandu, Nepal

Lukas Radbruch MD, Chair of Palliative Medicine, University Hospital Bonn, Bonn, Germany, and Director of the Center of Palliative Care, Malteser Hospital Seliger Gerhard Bonn / Rhein-Sieg, Germany.

\section{Corresponding author:}

Richard A. Powell, Director, MWAPO Health Development Group, PO Box 459-00621, Village Market, Nairobi, Kenya

E-mail: richard2powell@yahoo.co.uk

Tel: +254725709104

Word count: 1,032 


\section{Providing palliative care in humanitarian crises:}

\section{Always something to offer}

Over 128.6 million people across 33 countries require life-saving humanitarian assistance,${ }^{1}$ with 92.8 million particularly vulnerable, necessitating a call for an "unprecedented humanitarian response."2

Reacting to the current migration crisis, the need for a common multi-faceted framework has been recognized. Palliative care, however, has been overwhelmingly omitted from this and other humanitarian crises. ${ }^{3}$ Palliative care is "an approach that improves the quality of life of patients and their families facing the problems associated with lifethreatening illness, through the prevention and relief of suffering". ${ }^{4}$ We propose holistic palliative care as an integral component of relief strategies.

Palliative care is especially applicable in these humanitarian scenarios: (i) in protracted humanitarian crises, for patients with life-limiting illnesses who experience interruptions in their pre-crisis palliative care or whom have had unmet palliative care needs exacerbated as a result of it. The elderly are the most prominent group here, with their vulnerability and poorly identified and understood needs ${ }^{5}$; (ii) in the context of high death toll, mass casualty events, where resources are overwhelmed by casualties with variable condition severities, and individuals are triaged according to their survival likelihood; (iii) in communicable disease outbreaks with high mortality and limited 
therapeutic interventions, where relief of suffering can be the primary treatment option available (e.g., Ebola); (iv) in refugee and displaced persons camps, where a proportion of individuals require palliative care during a period of transition through the camp.

No formal measures exist of the extent of suffering during such crises, including the number of individuals who could benefit from palliative and / or end-of-life (EoL) care. The reference point for deaths in the UK under 'normal' circumstances is one percent of the population. ${ }^{6}$ There are crises where the percentage of people requiring palliative and EoL care would far exceed that. However, reliable estimates are non-existent, an information deficit that poses a serious programmatic challenge.

Triage systems in humanitarian settings, particularly in acute ones, have low sensitivity to the need for palliative care. They are daily management tools within civilian emergency departments aiming to achieve "the most for the most" by a process of determining patients' treatment priorities based on their condition severity. One of the most widely used triage systems, the five-level ' $T$ ' (Treatment) system, has category T4 (expectant priority) for those unlikely to survive despite the best available lifesaving care. ${ }^{7}$ Although casualties classified as "expectant" require palliative care to alleviate suffering, their treatment can be seen as diverting resources from salvageable patients and therefore may be neglected. Mass casualty, as opposed to routine clinical, triage is therefore predicated on the notion that care provided to those with unsurvivable injuries is an unreasonable use of resources, irrespective of the moral quandary faced by medical teams. ${ }^{8}$ Here the narrative focuses on the 'realm of the possible'. Palliative 
care, in contrast, tends to be relegated to the domain of the unfeasible or impossible, allowing preventable suffering to occur.

Palliative care provision in disaster settings is also vulnerable to rapid evacuation needs, leaving some patients unattended or subject to euthanasia proposals. ${ }^{9}$ Even where immediacy is not a pressing consideration, palliation is still often neglected, sometimes as a consequence of the surrounding unconducive low-resource environment. For example, during the Ebola crisis, palliative and supportive measures were essential care elements which could have been systematically implemented. ${ }^{10}$ In the absence of palliative care specialists, overburdened healthcare providers struggled, felt defeated and revealingly expressed frustration at feeling forced "to turn our treatment facilities into palliative care facilities". ${ }^{11}$

It is now time to ask if the standard humanitarian response of saving lives to minimize suffering should be re-imagined as a paradigm of saving lives and minimizing suffering. If we agree with the latter critical conceptualization, palliative care must be recognized as an incontestable part of a larger holistic reaction to such crises. Existing standards of crisis setting clinical care emphasize dying patients are treated with respect, accompanied, provided with pain relief and have other severe symptoms relieved to ensure dying is as comfortable and meaningful as possible. Providing palliative care is a means of upholding these tenets without neglecting the imperative to save lives.

Globally, palliative care service development is incommensurate with need $;{ }^{12}$ this 
shortcoming is particularly stark in humanitarian settings. So why is the humanitarian response narrative predominantly devoid of the palliative care voice? One possible explanation is the humanitarian community's suboptimal awareness of palliative care's goals. The approach appears as a poorly prioritized EoL intervention applying exclusively when all curative treatments are redundant, when there is "nothing left to offer", rather than to minimize patients' suffering and maximize their quality of life.

The lack of specific palliative care guidance in humanitarian standards also precludes humanitarian workers from applying consistently good practices when faced with palliative and EoL care needs. This is especially the case for essential medicines (a high priority of palliative care strategies) - such as highly affordable oral morphine resulting in ineffective pain management or, at worst, treating patients as if they are already deceased. Palliative care standards should include, at the very least: basic palliative care training for all humanitarian health workers; the addition of essential medicines for palliation into medications kits; guidance and tools on essential palliative care practices; and recommendations for creating a supportive policy environment. This should include the development of minimum palliative care standards for The Sphere Project humanitarian handbook, a publication endorsed by the majority of nongovernmental health agencies and international humanitarian organisations. Research on the topic is also urgently needed, including: baseline palliative care needs assessments; costs and effectiveness of palliative care interventions; surveys on humanitarian practitioners' knowledge, attitudes and practices; and the scoping of humanitarian agencies' work in this field. In the medium- to long-term, measures of 
success will include the integration of basic palliative care standards in organisational responses; a workforce trained in such standards; and the prominence of palliative care in global human rights dialogue.

The palliative care community must unite to offer workable and sustainable solutions in conjunction with humanitarian partners as part of an integrated disaster response package. In addition to saving lives, the relief of suffering among the severely ill and dying must be enabled during a humanitarian response. There is always something to offer, even at the end of life.

\section{Authors' contributions}

RAP led on the initial drafting of the paper (including literature search), which was reviewed and revised by LS, EN, BS, MP, JM, DM and LR.

\section{Declaration of interests}

LS and EN reports grants from ELRHA (R2HC) during the conduct of the study. All other authors have nothing to disclose.

\section{Funding source}

Unfunded work. 


\section{References}

1 United Nations Office for the Coordination of Humanitarian Affairs (OCHA). Global Humanitarian Overview 2017: A consolidated appeal to support people affected by disaster and conflict. http://www.unocha.org/stateofaid/ (accessed Feb 22, 2017).

2 Sengupta S. 60 Million People Fleeing Chaotic Lands, U.N. says. New York Times, Jun 18, 2015. www.nytimes.com/2015/06/18/world/60-million-people-fleeingchaotic-lands-un-says.html? $r=0$ (accessed Sep 17, 2016).

3 Marston J, De Lima L, Powell RA; Palliative Care in Complex Humanitarian Emergencies Network. Palliative care in complex humanitarian crisis responses. Lancet 2015; 386: 1940.

4 World Health Organization. WHO definition of palliative care. http://www.who.int/cancer/palliative/definition/en/ (accessed Sep 17, 2016).

5 Karunakara U, Stevenson F. Ending neglect of older people in the response to humanitarian emergencies. PLoS Med 2012; 9: e1001357.

6 Dying Matters Coalition. Finding your 1\% campaign. http://www.dyingmatters.org/gp page/about-campaign (accessed Sep 17, 2016).

7 Mackway-Jones K (ed.). Major Incident Medical Management and Support: The Practical Approach at the Scene, $3^{\text {rd }}$ ed. London: Blackwell, 2012.

8 Goodman A, Black L. The challenge of allocating scarce medical resources during a disaster in a low income country: A case study from the 2010 Haitian earthquake. Palliat Med Hosp Care Open J 2015; 1: 24-29.

9 Holt GR. Making difficult ethical decisions in patient care during natural disasters and other mass casualty events. Otolaryngol Head Neck Surg 2008; 139: 181-186. 
10 Dhillon P, McCarthy S, Gibbs M, Sue K. Palliative care conundrums in an Ebola treatment centre. BMJ Case Rep 2015; Sep 10; 2015.

11 Gillis C. The Interview: An MSF doctor on the battle against Ebola: Dr. Tim Jagatic on his Ebola patients, working in a haz-mat suit when it's $40^{\circ} \mathrm{C}$, and the agony of knowing the right help is out there. MacLean's Magazine. Oct 24, 2014.

http://www.macleans.ca/news/world/the-interview-an-msf-doctor-on-the-battleagainst-ebola/ (accessed Sep 17, 2016).

12 Krakauer E, Rajagopal MR. End-of-life care across the world: A global moral failing. The Lancet 2016; 388: 444-446. 